\title{
Work-Related and Personal Factors in Shoulder Disorders Among Electronics Workers
}

Po-Ching Chu

National Taiwan University College of Medicine and National Taiwan University Hospital

Tyng-Guey Wang

National Taiwan University College of Medicine

Yue Leon Guo ( $\square$ leonguo@ntu.edu.tw )

National Taiwan University College of Medicine https://orcid.org/0000-0002-8530-4809

\section{Research article}

Keywords: electronics industry, electronics, socio-demographic

Posted Date: September 28th, 2020

DOl: https://doi.org/10.21203/rs.3.rs-76615/v1

License: @ (1) This work is licensed under a Creative Commons Attribution 4.0 International License. Read Full License

Version of Record: A version of this preprint was published at BMC Public Health on August 9th, 2021. See the published version at https://doi.org/10.1186/s12889-021-11572-4. 


\section{Abstract}

Background The electronics industry is one of the largest global industries, and significant numbers of workers are engaged in this industry. Evidence suggests two associations: between ergonomic risks and shoulder disorders, and between psychological stress and psychological problems among workers in this industry. There have been very few investigations on ergonomic risks, psychological stress, and gender effect for shoulder disorders in this industry. This study aimed to explore personal and work-related factors associated with shoulder disorders, and to investigate the combined effect of similar ergonomic risk factors.

Methods In this cross-sectional study, 931 workers aged 20 to 58 from an electronics factory were recruited. Nordic musculoskeletal questionnaire was used to assess shoulder symptoms. The socio-demographic factors and work-related factors, including psychological stress, were assessed. 100 random sample workers with shoulder symptoms underwent a standardized clinical test for the evaluation of subacromial impingement syndrome. The ergonomic risks were assessed by the risk filter of "Upper limb disorders in the workplace", including repetition, posture, force, vibration, and duration of exposure.

Results The prevalence of shoulder symptoms was $30.5 \%$, and $19 \%$ of those with shoulder symptoms had subacromial impingement syndrome. In multivariable analyses, older age (adjusted odds ratio $(\mathrm{aOR})=1.37,95 \% \mathrm{Cl} 1.01-1.86)$, repetition $(\mathrm{aOR}=1.73,95 \% \mathrm{Cl} 1.15-2.60)$ and posture $(\mathrm{aOR}=1.85,95 \% \mathrm{Cl} 1.10-3.11)$ were associated with shoulder symptoms. About the gender effect, older age $(\mathrm{aOR}=1.46,95 \% \mathrm{Cl} 1.01-2.11)$, repetition $(\mathrm{aOR}=1.64,95 \% \mathrm{Cl} 1.00-2.68)$, posture $(\mathrm{aOR}=1.89$, $95 \% \mathrm{Cl} 1.01-3.52)$, and force $(\mathrm{aOR}=1.68,95 \% \mathrm{Cl}$ 0.99-2.85) were associated with shoulder symptoms in men, while repetition $(\mathrm{aOR}=2.73,95 \% \mathrm{Cl} 1.52-4.93)$ and posture $(\mathrm{aOR}=2.12,95 \% \mathrm{Cl} 0.99-4.57)$ were associated with the symptoms in women.

Conclusions This study implies that repetition and posture were important risk factors for shoulder disorders in the electronics industry. The risk showed gender differences, and force was more important for shoulder disorders in men. Such information is useful to help occupational health practitioners and policy makers conduct preventive programs on shoulder disorders in this working population. Future longitudinal studies on work-related shoulder disorders are warranted.

\section{Background}

The electronics industry is estimated to engage 18 million workers worldwide in 2010 [1] and is the leading industry in many East Asia countries including Japan, South Korea, and Taiwan. Over 800,000 employers belong to the industry in Taiwan in 2016 [2]. Besides chemical and physical hazards, the work environment of the industry may contain ergonomic hazards, such as repetition, lifting, and awkward posture [3-6], making the population vulnerable to develop musculoskeletal disorders.

The manufacture of thin film transistor liquid crystal display (TFT-LCD) is one common type of the electronics industry. There are three processes during the manufacture of TFT-LCD panels including array, cell, and module assembly processes. The array process is similar to the semiconductor manufacturing process [7], which has been linked to upper limb musculoskeletal symptoms. A dose-response effect between the symptoms and working hours was found [8]. Next, the cell process joins the arrayed substrate to the color-filter substrate, and then the space between two substrates was filled with liquid crystal. Finally, the module assembly process requires assembling components such as circuits and backlight units to the glass panel. In the module department of a TFT-LCD factory, Lu et al. have found that the most prevalent locations of musculoskeletal symptoms was the shoulder (59.8\%) [9]. They also indicated that a high work-related ergonomic risk for the shoulder area was associated with following factors: poor arm support, mismatched workstation design, and the workers' anthropometry. In another similar study of an electronic assembly factory, Pullopdissakul et al. [10] assessed four work-related ergonomic hazards, including repetitive motion, high force, awkward posture, and contact stress. They found that the ergonomic hazards were associated with upper limb musculoskeletal disorders. Furthermore, the exposure profile 
in settings of the electronics industry may be characterized by combined ergonomic exposures. Although several studied have assessed the combined effect of ergonomic risks for musculoskeletal disorders [11-13], the investigation on whether the combination of two or more similar ergonomic risks increases the risk of shoulder disorders is rarely addressed in the electronics industry. For example, whether workers exposed to both awkward joint positions and joints held in fixed positions have high odds of shoulder disorders compared to those with only one exposure.

About the work environment, the manufacturing process of microelectronics products requires the protection of special work environments, namely clean rooms, where employees need to be fully covered in protective suites [14]. When the workers stay fully suited while performing repetitive tasks during the entire work shift, these head-to-toe garments can cause discomfort and limit the range of body movements. Furthermore, the electronics industry is known for its rapid technological innovation, global competition, operating on shift work, and performance-based pay systems $[3,15]$. The association between psychological stress and psychological problems in the industry has been identified [6], but very few studies investigated the psychosocial risk factors for shoulder disorders.

Although current evidence suggested that personal factors (i.e. age and gender), ergonomic risks, and psychological stress were associated with shoulder disorders, there have been very few investigations on all three factors for shoulder disorders in the electronics industry. An understanding of modifiable risk factors is critical to facilitating future efforts to prevent shoulder disorders in the industry. Therefore, the first objective of this study was to explore potential work-related and personal factors among workers with shoulder disorders in a representative TFT-LCD factory. The second objective was to examine the combined effect of similar ergonomic risk factors for shoulder disorders.

\section{Methods}

\section{Study population}

This cross-sectional study was combined with the regular medical examination of a selected electronics enterprise in 2010. Participants were recruited from the electronics enterprise. Participants aged 20 to 58 years and working in the enterprise were assessed for eligibility. Exclusion criteria were foreign nationals in Taiwan. Based on a previous study for shoulder pain in working population [16], adjusted odds ratio $=1.73$, one year cumulative incidence rate $=6.6 \%$ was used to sample size calculation. The calculation showed that a total of 655 patients would be required at a significance level of 0.05 and $95 \%$ power. A total of 1,029 eligible participants were provided with information on the study, such as study purpose and methods. 29 participants refused to join the study (response rate: 97\%). The final sample included 931 participants after excluding those with missing values for age $(n=44)$ and ergonomic risks $(n=25)$ (Fig. 1).

\section{Outcome Measures}

The definition of shoulder symptoms within 12 months preceding the survey was based on the Nordic questionnaire [17]. To understand the clinical diagnosis of the shoulder symptoms, the objective indicators based on special physical examination of the shoulder were applied in this study. Physical examination was performed by an occupational physician using a standardized clinical procedure. The procedure strictly followed the clinical tests of the European consensus criteria document for the evaluation of the work-relatedness of upper extremity musculoskeletal disorders [18]. In the study, participants with shoulder symptoms were randomly assigned into one group, with one hundred participants receiving the physical examination. The type of randomization was a simple randomization. The sequence generation was according to a computer-generated list of random numbers.

\section{Assessment Of Work-related Ergonomic Risk Factors}


The assessment of work-related ergonomic risk factors was based on the Risk Filter of "Upper limb disorders in the workplace" issued by the Health and Safety Executive, UK [19], and it is a technique for assessing the exposure to risk factors for work-related upper limb musculoskeletal disorders. The main feature is a checklist for upper limb disorders hazards in the workplace to assess the four categories of ergonomic risk factors: movement frequency, posture, load/force, vibration, and consider the duration of exposure, and this method is a simpler observational method which has the benefits of being low-priced and practical for use in the workplaces, and appears to offer the levels of generality and exactness matched to the needs of occupational safety and health practitioners [20]. For repetition-related risks, there were 3 items about repetition: (1) repeating the same motions every few seconds, (2) a sequence of movements repeated more than twice per minute, and (3) more than $50 \%$ of the cycle time involved in performing the same sequence of motions. There were 6 items about posture: (1) large range of joint movement such as side to side or up and down; (2) awkward or extreme joint positions; (3) joints held in fixed positions; (4) stretching to reach items or controls; (5) twisting or rotating items or controls; (3) working overhead. The picture forms of different postures were used to facilitate participants' understanding. Force-related risks were assessed by 6 items: (1) pushing, pulling, moving things (including with the fingers or thumb); (2) grasping / gripping; (3) pinch grips i.e. holding or grasping objects between thumb and finger; (4) steadying or supporting items or work pieces; (5) shock and /or impact being transmitted to the body from tools or equipment; (6) objects creating localized pressure on any part of the upper limb. There was one item assessing vibration: use any powered hand-held or hand-guided tools or equipment / hand-feed work pieces to vibrating equipment. Furthermore, the definition of the duration of exposure for repetition, posture, and force was more than 2 hours per shift, and the definition for vibration was regular with some point during most shifts. To assess the combined effect of similar ergonomic risks, the individual risks for the categories of repetition, posture, and force were used to stratify the participants into three groups: the high risk ( $\geq 3$ items), low risk (1-2 items), and no risk (no item) groups, except for the category of vibration.

\section{Assessment Of Associated Variables}

A structured self-administered questionnaire was distributed to collect the data, and the questions included the following aspects: (1) personal factors, including basic demographic information (i.e. age and gender), and body mass index; (2) work-related factors, including seniority, psychological stress, and work-related physical fatigue. Regarding the assessment of psychological stress, because the industry is highly globally competitive and requires a high level of information security, it would be impossible to administer detailed psychological stress assessment, such as job demand-control model and effort-reward imbalance model.

Therefore, a single-item question was used as a surrogate, and developed from the need to indicate stress at work based on the previous psychological stress measure [21, 22]. The definition of stress was feeling irritable, anxious, or having sleep problems as a consequence of work-related issues. The participants were asked to report the frequency of stress at work, and the response options were four-point categorical scale: (1) never; (2) some periods; (3) several periods; (4) permanent stress. Regarding the assessment of work-related physical fatigue, it was based on the method of Skarpsno et al. [23]. Participants were asked: 'Is your work so physically demanding that you are often physically worn out after a day's work?', and the response options were 'never, or almost never', 'seldom', 'quite often', and 'yes, nearly always'.

\section{Statistical analysis}

We examined the baseline characteristics including age, gender, body height, body weight, body mass index, psychological stress, work-related physical fatigue, and ergonomic risk factors among the participants. The descriptive results of continuous variables were expressed as mean (standard deviation), and the categorical variables were presented as numbers and percentages. The continuous and categorical data were compared between the participants with and without shoulder symptoms. For categorical data, Chi-squared tests was used. Shapiro-Wilk test was applied to test the normal distribution for the continuous data, including body height, body weight, body mass index, and experience at the job, and 
Wilcoxon rank-sum test was applied for not normal distribution. We used univariable and multivariable logistic regression analyses to estimate the odds ratios (OR) and 95\% confidence interval $(95 \% \mathrm{Cl})$ for the association between personal factors, work-related factors, ergonomic risk factors, and shoulder symptoms. About ergonomic risk factors, high or low risk groups were compared with no risk group. Multivariable logistic regression analysis was performed to adjust for variables having significant associations in the univariable analysis. The multiple regression analysis included two models. In the first model, the selection of variables was from significant variables in the univariate analyses, and the setting of model selection was stepwise. In the second model, the selection of variables was from significant variables in the univariate analyses, and the setting of model selection was nil. Population attributable risk (PAR) was calculated to estimate the contribution of each risk factor to shoulder symptoms. PAR indicates that the incidence of shoulder symptoms in the workers would be prevented if the risk factor did not exist. The adjusted PAR was calculated using the formula $1-[\Sigma$ (number of cases within specific stratum/relative risk of specific stratum)/total number of cases] [24]. The present study applied gender-stratified analyses rather than gender-adjusted analyses as recommended by Silverstein et al. [25] to better understand the potential gender differences in the risk for shoulder symptoms. A p-value of $<0.05$ was considered to indicate a statistically significant difference. All analyses were performed using SAS software version 9.4 (SAS Institute, Cary, North Carolina).

\section{Results}

The basic characteristics of the study population are presented in Table 1. We recruited 931 participants, including 284 workers $(30.50 \%)$ with shoulder symptoms and 647 workers $(69.50 \%)$ without shoulder symptoms. Although the mean ages (standard deviation) were $38.3(7.0)$ and $37.4(7.4)$ years for people with and without shoulder symptoms $(p=0.10)$, a higher proportion of people with shoulder symptoms were over 40 years of age compared with those with no symptoms (p $=0.04$ ). More workers were men in both groups, but the proportion of women having shoulder symptoms was significantly higher than those with no symptoms $(p=0.03)$. The difference between two groups for psychological stress was not significant $(p=0.14)$, and it was also not significant $(p=0.14)$ for work-related physical fatigue. About the results of physical examination of shoulders, a random sample of 100 workers (35.2\%) selected from total 284 workers with shoulder symptoms received the examination. Among them, $19 \%$ had subacromial impingement syndrome confirmed by physical examination. 
Table 1

Basic characteristics of study population and distribution of shoulder symptoms

\begin{tabular}{|c|c|c|c|c|c|}
\hline \multirow[b]{2}{*}{ Variables } & \multicolumn{2}{|c|}{ No shoulder symptoms } & \multicolumn{3}{|c|}{ Shoulder symptoms } \\
\hline & $n=647$ & & $\mathrm{n}=284$ & & $\mathrm{p}$-value \\
\hline \multicolumn{6}{|l|}{ Age } \\
\hline$\leqq 40$ & 442 & $(68.3 \%)$ & 174 & $(61.3 \%)$ & 0.04 \\
\hline$>40$ & 205 & (31.7\%) & 110 & $(38.7 \%)$ & \\
\hline \multicolumn{6}{|l|}{ Gender } \\
\hline Female & 174 & $(26.9 \%)$ & 96 & $(33.8 \%)$ & 0.03 \\
\hline Male & 473 & $(73.1 \%)$ & 188 & $(66.2 \%)$ & \\
\hline Body height & 167.4 & $(8.3)$ & 167.0 & $(8.8)$ & 0.39 \\
\hline Body weight & 70.0 & $(13.6)$ & 68.8 & $(14.8)$ & 0.06 \\
\hline Body mass index & 24.9 & $(4.1)$ & 24.5 & $(4.1)$ & 0.13 \\
\hline Experience at the job (years) & 5.3 & $(5.6)$ & 5.2 & $(5.1)$ & 0.69 \\
\hline Psychological stress $^{a}$ & & & & & 0.14 \\
\hline Never & 72 & $(11.1 \%)$ & 24 & $(8.5 \%)$ & \\
\hline Some periods & 274 & $(42.4 \%)$ & 120 & $(42.3 \%)$ & \\
\hline Several periods & 262 & $(40.5 \%)$ & 112 & $(39.4 \%)$ & \\
\hline Permanent & 39 & $(6.0 \%)$ & 28 & $(9.9 \%)$ & \\
\hline Work-related physical fatigue ${ }^{a}$ & & & & & 0.06 \\
\hline Never or almost never & 52 & $(8.0 \%)$ & 15 & $(5.3 \%)$ & \\
\hline Seldom & 272 & $(42.0)$ & 101 & $(35.6 \%)$ & \\
\hline Quite often & 279 & $(43.1 \%)$ & 143 & $(50.4 \%)$ & \\
\hline Yes, nearly always & 44 & $(6.8 \%)$ & 25 & $(8.8 \%)$ & \\
\hline
\end{tabular}

Ergonomic risk factors for the workers with and without shoulder symptoms are presented in Table 2. Compared with the no symptom group, the group with shoulder symptoms had significantly higher rates of repetition risks, including working with repeating same motion every few seconds, performing a sequence over twice per minute, and over half of the cycle time in the same sequence of motions (all p-values $<0.01$ ). For the risks related to working postures, the group with shoulder symptoms had significantly higher rates of working with awkward/extreme joint positions, joints held in fixed positions, stretching to reach items, twisting/rotating items, and working overhead (all p-values $<0.01$ ). For force-related risk, the group with shoulder symptoms had significantly higher rates of working with pushing/pulling/moving things, grasping/gripping, pinch grips, shock/impact being transmitted to the body, and localizing pressure on upper limb ( $p \leq$ 0.03). There was no significant difference in the proportions of workers using vibrating equipment between the groups with/without shoulder symptoms $(p=0.24)$. Furthermore, the combined effect of similar ergonomic risks for the proportion of shoulder symptoms is shown in Fig. 2. For the three different risk groups, the group with high combined repetition risks 
had higher proportions of shoulder symptoms than the group with low risks ( $\mathrm{P}$ for trend $<0.01)$, and similar trends were found for the posture and force risks (two P for trend < 0.01).

Table 2

Distribution of biomechanical risks for shoulder symptoms

\begin{tabular}{|c|c|c|c|c|c|}
\hline \multirow[b]{2}{*}{ Variables } & \multicolumn{2}{|c|}{$\begin{array}{l}\text { No shoulder } \\
\text { symptoms }\end{array}$} & \multicolumn{3}{|c|}{$\begin{array}{l}\text { Shoulder } \\
\text { symptoms }\end{array}$} \\
\hline & \multicolumn{2}{|c|}{$n=647$} & \multicolumn{2}{|c|}{$n=284$} & $\begin{array}{l}\mathrm{p}- \\
\text { value }\end{array}$ \\
\hline \multicolumn{6}{|l|}{ Repetition risk } \\
\hline Repeating the same motions every few seconds & 199 & $(30.8 \%)$ & 135 & $(47.5 \%)$ & $\dot{0} 01$ \\
\hline A sequence of movements repeated more than twice per minute & 220 & $(34.0 \%)$ & 146 & $(51.4 \%)$ & $\dot{0} 01$ \\
\hline $\begin{array}{l}\text { More than } 50 \% \text { of the cycle time involved in performing the same } \\
\text { sequence of motions }\end{array}$ & 249 & $(38.5 \%)$ & 157 & $(55.3 \%)$ & $<.01$ \\
\hline \multicolumn{6}{|l|}{ Posture risk } \\
\hline Large range of joint movement such as side to side or up and down & 107 & $(16.5 \%)$ & 59 & $(20.8 \%)$ & 0.12 \\
\hline Awkward or extreme joint positions & 54 & $(8.3 \%)$ & 53 & $(18.7 \%)$ & $<.01$ \\
\hline Joints held in fixed positions & 169 & $(26.1 \%)$ & 126 & $(44.4 \%)$ & $<.01$ \\
\hline Stretching to reach items or controls & 201 & $(31.1 \%)$ & 115 & $(40.5 \%)$ & $\begin{array}{l}< \\
0.01\end{array}$ \\
\hline Twisting or rotating items or controls & 177 & $(27.4 \%)$ & 113 & $(39.8 \%)$ & $\dot{0} 01$ \\
\hline Working overhead & 90 & $(13.9 \%)$ & 59 & $(20.8 \%)$ & $<.01$ \\
\hline \multicolumn{6}{|l|}{ Force risk } \\
\hline Pushing, pulling, moving things (including with the fingers or thumb) & 244 & $(37.7 \%)$ & 140 & $(49.3 \%)$ & $<.01$ \\
\hline Grasping/gripping & 240 & $(37.1 \%)$ & 146 & $(51.4 \%)$ & $<.01$ \\
\hline Pinch grips i.e. holding or grasping objects between thumb and finger & 177 & $(27.4 \%)$ & 98 & $(34.5 \%)$ & 0.03 \\
\hline Steadying or supporting items or work pieces & 142 & $(21.9 \%)$ & 78 & $(27.5 \%)$ & 0.07 \\
\hline $\begin{array}{l}\text { Shock and/or impact being transmitted to the body from tools or } \\
\text { equipment }\end{array}$ & 50 & $(7.7 \%)$ & 35 & $(12.3 \%)$ & 0.03 \\
\hline Objects creating localized pressure on any part of the upper limb & 68 & $(10.5 \%)$ & 50 & $(17.6 \%)$ & $\dot{0} 01$ \\
\hline \multicolumn{6}{|l|}{ Vibration risk } \\
\hline $\begin{array}{l}\text { Use any powered hand-held or hand-guided tools or equipment/ hand- } \\
\text { feed work pieces to vibrating equipment }\end{array}$ & 51 & $(7.9 \%)$ & 29 & $(10.2 \%)$ & 0.24 \\
\hline
\end{tabular}


The univariable and multivariable-adjusted odds ratios for the associations between the risk factors and shoulder symptoms are presented in Table 3. Older age $(\mathrm{OR}=1.36,95 \% \mathrm{Cl}=1.02-1.82$, using age $\leqq 40$ as the reference) and female gender $(\mathrm{OR}=1.39,95 \% \mathrm{Cl}=1.03-1.88$, using male as the reference) were significantly associated with shoulder symptoms. Permanent psychological stress was significantly associated $(\mathrm{OR}=2.15,95 \% \mathrm{Cl}=1.10-4.21$, using never stress as the reference). Among the ergonomic risk factors, high repetition-related risk $(\mathrm{OR}=2.45,95 \% \mathrm{Cl}=1.78-3.37$, using no repetition risk as the reference) was significantly associated with shoulder symptoms. Low and high posture-related risks $(O R=2.01$, $95 \% \mathrm{Cl}=1.43-2.82 ; \mathrm{OR}=2.34,95 \% \mathrm{Cl}=1.65-3.30$, using no posture risk as the reference) were significantly associated with shoulder symptoms. Low and high force-related risks $(\mathrm{OR}=2.05,95 \% \mathrm{Cl}=1.43-2.95 ; \mathrm{OR}=1.76,95 \% \mathrm{Cl}=1.27-2.44$, using no force risk as the reference) were significantly associated with shoulder symptoms. Therefore, the OR of the personal factors (e.g. age, gender) were no more than 1.39, and the OR of the three ergonomic risk factors (repetition, posture, and force) were 1.76 to 2.45 (high risk, compared with no risk). The findings supported that the ergonomic risk factors had higher contribution to shoulder symptoms than personal factors. About the multiple regression analysis, the model selection by stepwise was applied to the first model. The findings showed that high repetition-related risk $(O R=1.75$, $95 \% \mathrm{Cl}=1.19-2.60$, using no repetition risk as the reference), and low and high posture-related risks $(\mathrm{OR}=1.66,95 \% \mathrm{Cl}=$ $1.13-2.45 ; \mathrm{OR}=1.74,95 \% \mathrm{Cl}=1.14-2.66$, using no posture risk as the reference) were significantly related to shoulder symptoms. In the second model, no model selection was applied. The findings showed that older age $(\mathrm{OR}=1.37,95 \% \mathrm{Cl}=$ $1.01-1.86$, using age $\leqq 40$ as the reference) was significantly associated with shoulder symptoms. High repetition-related risk $(\mathrm{OR}=1.73,95 \% \mathrm{Cl}=1.15-2.60$, using no repetition risk as the reference), and low and high posture-related risks (OR = $1.61,95 \% \mathrm{Cl}=1.06-2.45 ; \mathrm{OR}=1.85,95 \% \mathrm{Cl}=1.10-3.11$, using no posture risk as the reference) were significantly related to shoulder symptoms. In the two models, gender, body mass index, psychological stress, work-related physical fatigue, force risk, and vibration were not significantly associated with shoulder symptoms. Furthermore, the adjusted PAR was $26.80 \%$ for posture, followed by repetition risks (18.65\%). 
Table 3

Univariate and multivariate logistic regression analysis of factors influencing shoulder symptoms

\begin{tabular}{|c|c|c|c|c|c|c|c|}
\hline & \multicolumn{2}{|c|}{ Crude } & \multicolumn{2}{|c|}{ First model ${ }^{d}$} & \multicolumn{2}{|c|}{ Second model ${ }^{e}$} & \multirow[t]{2}{*}{ aPAR } \\
\hline & OR & $95 \% \mathrm{Cl}$ & OR & $95 \% \mathrm{Cl}$ & OR & $95 \% \mathrm{Cl}$ & \\
\hline Age $>40 /$ Age $\leqq 40$ & 1.36 & $1.02-1.82^{\mathrm{a}}$ & & & 1.37 & $1.01-1.86^{a}$ & \\
\hline Female / Male & 1.39 & $1.03-1.88^{\mathrm{a}}$ & & & 1.03 & $0.74-1.43$ & \\
\hline Body mass index & 0.98 & $0.94-1.01$ & & & & & \\
\hline \multicolumn{8}{|l|}{ Psychological stress } \\
\hline Never & 1 & - & & & 1 & - & \\
\hline Some periods & 1.31 & $0.79-2.19$ & & & 1.28 & $0.76-2.16$ & \\
\hline Several periods & 1.28 & $0.77-2.14$ & & & 1.21 & $0.72-2.06$ & \\
\hline Permanent & 2.15 & $1.10-4.21^{\mathrm{a}}$ & & & 1.91 & $0.95-3.84$ & \\
\hline \multicolumn{8}{|c|}{ Work-related physical fatigue } \\
\hline Never or almost never & 1 & - & & & & & \\
\hline Seldom & 1.29 & $0.69-2.39$ & & & & & \\
\hline Quite often & 1.78 & $0.97-3.27$ & & & & & \\
\hline Yes, nearly always & 1.97 & $0.93-4.19$ & & & & & \\
\hline Repetition risk & & & & & & & 18.65 \\
\hline No & 1 & - & 1 & - & 1 & - & \\
\hline Low & 1.34 & $0.91-1.97$ & 1.03 & $0.67-1.58$ & 0.97 & $0.63-1.51$ & \\
\hline High & 2.45 & $1.78-3.37^{c}$ & 1.75 & $1.19-2.60^{b}$ & 1.73 & $1.15-2.60^{b}$ & \\
\hline Posture risk & & & & & & & 26.80 \\
\hline No & 1 & - & 1 & - & 1 & - & \\
\hline Low & 2.01 & $1.43-2.82^{c}$ & 1.66 & $1.13-2.45^{b}$ & 1.61 & $1.06-2.45^{\mathrm{a}}$ & \\
\hline High & 2.34 & $1.65-3.30^{c}$ & 1.74 & $1.14-2.66^{a}$ & 1.85 & $1.10-3.11^{\mathrm{a}}$ & \\
\hline \multicolumn{8}{|l|}{ Force risk } \\
\hline No & 1 & - & & & 1 & - & \\
\hline Low & 2.05 & $1.43-2.95^{\mathrm{C}}$ & & & 1.38 & $0.91-2.12$ & \\
\hline High & 1.76 & $1.27-2.44^{\mathrm{b}}$ & & & 0.86 & $0.54-1.38$ & \\
\hline \multicolumn{8}{|l|}{ Vibration risk } \\
\hline No & 1 & - & & & & & \\
\hline
\end{tabular}




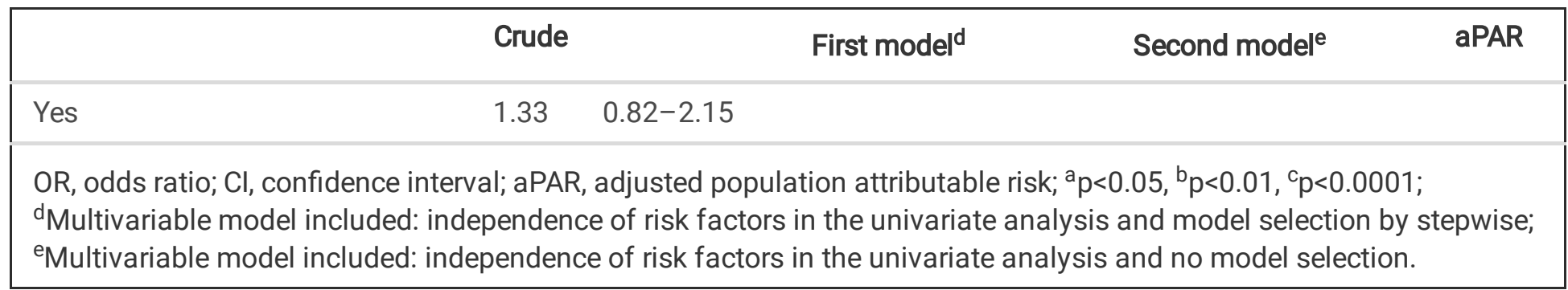

To identify possible gender-specific factors, the population were stratified by gender and the results are shown in Table 4 . The univariable regression analysis showed that older age, using age $\leqq 40$ as the reference, was significantly associated with shoulder symptoms only in men, and not in women. High repetition, low and high posture, and low and high force risks were significantly associated with shoulder symptoms in men. High repetition, and low and high posture risks were significantly associated with shoulder symptoms in women. Body mass index, and vibration were not significantly associated with shoulder symptoms in men and women. Psychological stress and work-related physical fatigue were significantly associated in women. Regarding the multiple regression analysis, in the first model for men, the findings showed that low and high posture-related risks $(\mathrm{OR}=1.79,95 \% \mathrm{Cl}=1.19-2.68 ; \mathrm{OR}=2.25,95 \% \mathrm{Cl}=1.46-3.46$, using no posture risk as the reference) were significantly associated with shoulder symptoms. In the second model for men, the findings showed that high repetition $(\mathrm{OR}=1.64,95 \% \mathrm{Cl}=1.00-2.68)$, and high posture $(\mathrm{OR}=1.89,95 \% \mathrm{Cl}=1.01-3.52)$ were significantly associated with shoulder symptoms. Force was approximately significant associated with shoulder symptoms $(p=0.05 ; O R=1.68,95 \% \mathrm{Cl}=0.99-2.85)$. In the first model for women, high repetition-related risk $(O R=2.73$, $95 \% \mathrm{Cl}=1.52-4.93$, using no repetition risk as the reference) was significant factors of having shoulder symptoms. In the second model for women, the findings showed that posture was approximately significant associated with shoulder symptoms $(p=0.05 ; O R=2.12,95 \% \mathrm{Cl}=0.99-4.57)$. Furthermore, a lower value in the higher category of force-related risks among overall population (Table 3), force-related risks among men workers (Table 4), and posture-related risks among women (Table 4) may be an indication of a healthy worker effect. 
Table 4

Univariate and multivariate logistic regression analysis of factors influencing shoulder symptoms, stratified by gender

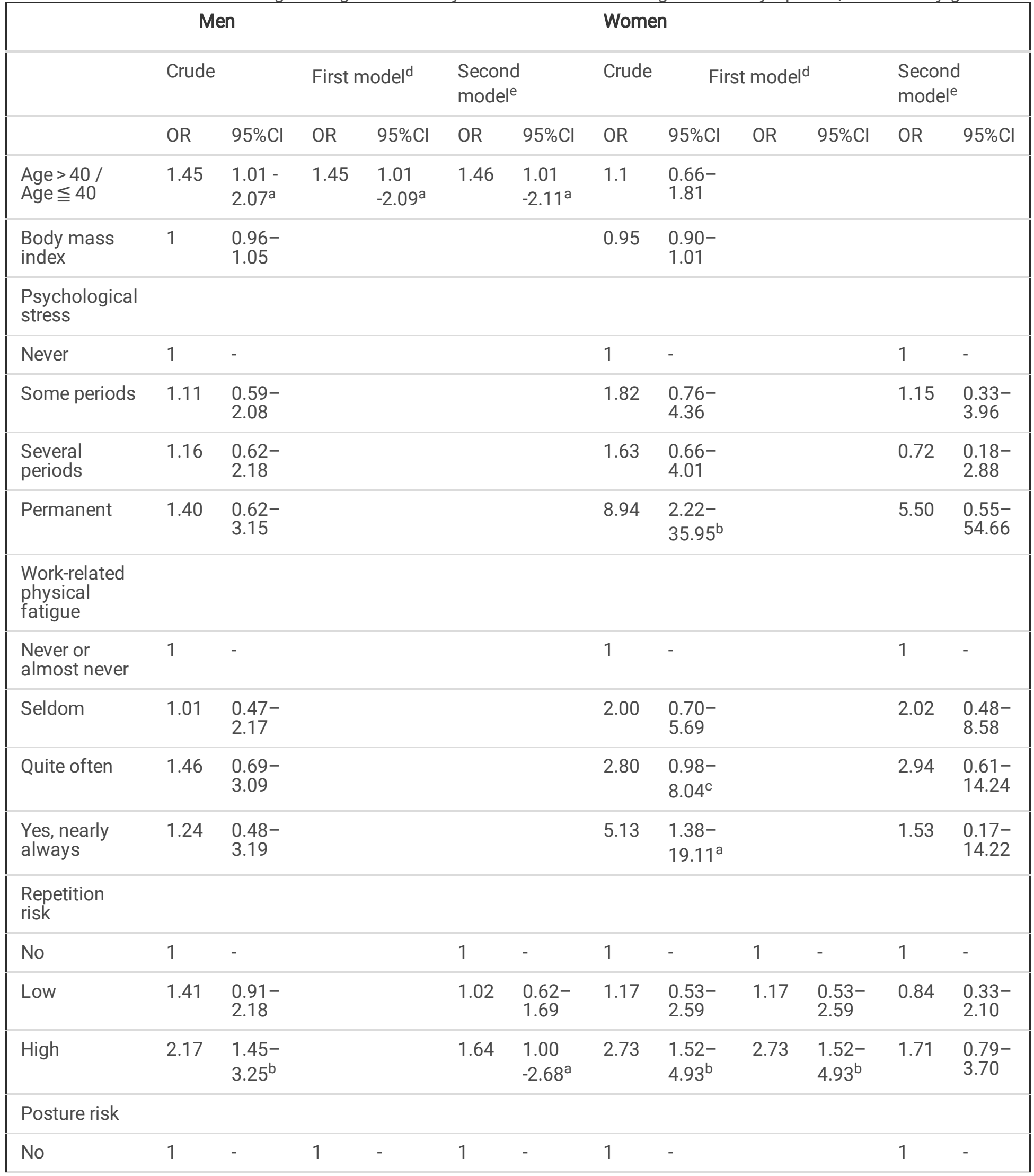

OR, odds ratio; $\mathrm{Cl}$, confidence interval; ${ }^{a} p<0.05,{ }^{b} p<0.01,{ }^{c} p=0.05$ (borderline significant); ${ }^{d}$ Multivariable model included: independence of risk factors in the univariate analysis and model selection by stepwise; ${ }^{e}$ Multivariable model included: independence of risk factors in the univariate analysis and no model selection. 


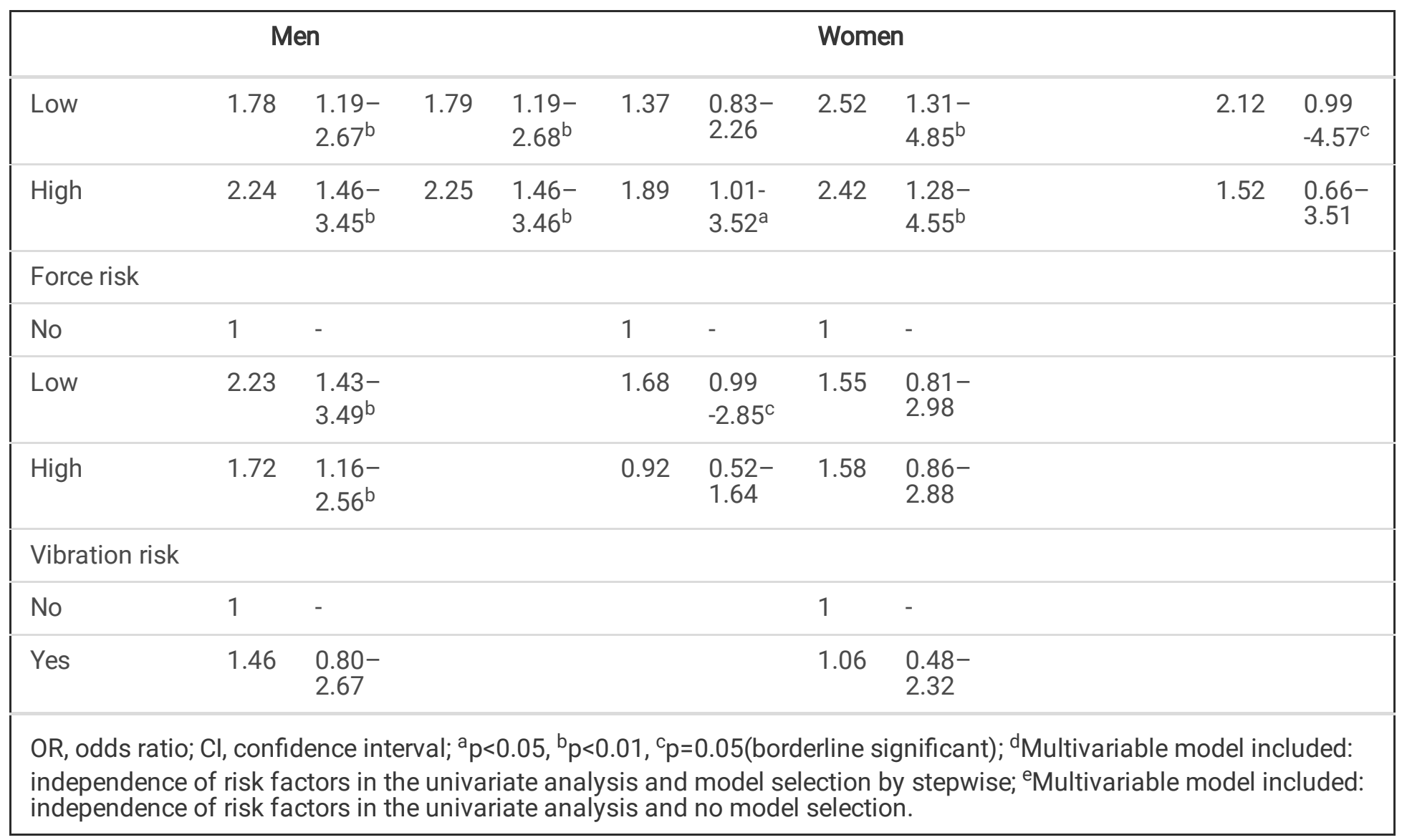

\section{Discussions}

The present study explored the work-related and personal factors among a special working population, the TFT-LCD factory workers. In the multiple regression, older age, repetition, and posture were associated with shoulder symptoms; however, psychological stress and work-related physical fatigue were not associated. Workers with more repetition, posture, or force risks reported a higher proportion of shoulder symptoms, and this findings support that the combined effect of similar ergonomic risks for shoulder disorders. This combined effect approach was similar to the Key Indicator Method for manual handling operations is to combine and sum the main risk factors of force, repetition, posture, and others to a single risk score [26]. Furthermore, we identified gender differences in the effect of exposure to the risk factors of shoulder symptoms. For men, older age, repetition, posture, and force were associated with shoulder symptoms. For women, repetition and posture were associated with shoulder symptoms. This finding implies that force was more important for shoulder disorders in men. Furthermore, permanent psychological stress was associated with shoulder symptoms, but the finding was not found after considering other factors, such as ergonomic risks. To the best of our knowledge, this is the first study to investigate shoulder symptoms and physical examination of subacromial impingement syndrome accompanied by potential personal factors, ergonomic risks, and psychological stress among workers in an electronics factory.

The ergonomic risks or musculoskeletal disorders among workers in the TFT-LCD industry is rarely addressed. Only two studies indicated that high ergonomic risks for the shoulder area were associated with poor arm support and the discrepancy between the workstation and the workers' anthropometry $[9,27]$. There was no comprehensive analysis which considers different ergonomic risks (e.g. repetition, posture, force, and vibration) as well as personal factors and psychological stress for shoulder disorders. Nevertheless, studies in the semiconductor industry, which shares similar work procedures with that of the TFT-LCD industry, have indicated that shoulder symptoms were among the most prevalent musculoskeletal disorders [28-30]. One of the earliest studies in 1986, Kilbom et al. indicated that flexion and abduction of the upper arm were associated with shoulder symptoms [28]. Chandrasakaran et al. showed that prolonged sitting and trunk bending was associated with shoulder symptoms [31]. Chee et al. indicated that prolonged sitting in awkward 
postures with the characteristics of a forward bent neck and tables that are too high may result in shoulder pain [7]. Furthermore, due to the high accuracy requirements for tasks such as inspection or manual assembly, workers tend to bend their necks forward to give optimal visual conditions and could cause shoulder symptoms [32]. Aghilinejad et al. found that the use of magnification loupes may improve the visibility of electronic parts as well as improving the postures of assembly workers and may reduce musculoskeletal discomfort [30]. The aforementioned findings were similar to that of the present study which showed that posture was an independent ergonomic risk for shoulder symptoms, indicating that awkward or extreme joint positions, joints held in fixed positions, stretching to reach items or controls, and working overhead were significant risk factors. The possible reasons accounting for the association between posture and shoulder symptoms is that arm elevation or prolonged sitting with awkward posture (e.g. bent neck) may put additional load on the musculoskeletal system of the shoulder. One of the main pathophysiological mechanisms of the shoulder disorder (e.g. subacromial impingement syndrome) is the compression of the tendons between the humeral head and the coracoacromial arch and ischemia by impingement or increased intramuscular pressure as a result of arm elevation [33].

About the association between vibration and shoulder symptoms, the meta-analysis indicated low to very low evidence for association between shoulder disorders and hand-arm vibration $(\mathrm{OR}=1.3)$ [34]. In positive association studies, the study populations were special working populations, such as forestry workers, rock drill workers, construction workers, and railroad engineers [35-38], and the place recruited was in hospital [39]. Hagberg et al. indicated that the exposure factors associated with rotator cuff tendinitis in the different occupational groups were not the same [40]. In the present study, the association was not found, which was similar to earlier studies for electronics workers [8,31]. It is possible that the difference in study populations or locations recruited may explain these inconsistent findings. The high prevalence for shoulder pain was found in the electronics industry and this could be related to repetitive lifting task, repetitive operating machine, and monotonous short cycle of tasks [7]. Chee et al. found that repetitive tasks could increase the risk of shoulder pain [41]. A longitudinal study in France indicated repetitive work under time constraints contributed to the development of chronic neck and shoulder disorders after adjustment of age [42]. Furthermore, Jonsson et al. showed that reorganizing monotonous and repetitive work into a more diverse pattern may improve work-related upper limb musculoskeletal disorders after a 2-year follow-up study [29]. These findings among electronics workers are consistent with the present study, which indicated that work which involves repeating the same motion every few seconds, a sequence of movements over twice per minute, and over half of the cycle time in the same sequence of motion were significant risk factors.

About the association between force and shoulder symptoms, one systematic review showed that shoulder load $(O R=2.0)$ and hand force exertion ( $\mathrm{OR}=1.5)$ were associated with shoulder disorders [34]. Another systematic review indicated that the occurrence of subacromial impingement syndrome was associated with high maximal voluntary contraction, lifting, and high hand force $(\mathrm{OR}=2.8-4.2)$ [43]. Repetitive tasks using mechanical force that put stress on small areas had increased the prevalence of neck or shoulder pain in department of manual assembly in 18 electronics factories [8]. One possible mechanism accounting for the association between force and shoulder symptoms is that the direction of the force performed increases muscular activity levels, especially in overhead work [44]. Similar to the above studies, the association between force and shoulder symptoms was found (crude OR $=1.76-2.05$ ) (Table 3), but the association was not found after multiple regression. One possible reason accounting for the no association is that the production process is usually automated and process changed to light object in the electronics industry.

About the gender differences, the association between shoulder symptoms and the frequency of forceful exertions was higher for women than men in a gender-stratified analysis [45]. Women are considered being at a higher risk of shoulder disorders (e.g. rotator cuff syndrome) than men, possibly reflecting both biological predisposition and exposure to workrelated repetitive biomechanical constraints [25,33]. The biological distinctions between men and women, including anatomy, strength, hormones, neuromuscular control, and musculoskeletal flexibility [46], suggest a different vulnerability to these work-related risk factors of shoulder disorder. In the association between force and shoulder symptoms was not found for women. The gender difference may result from differences in the type of task assigned, which means different exposures to the constraints at work [25,33]. Women and men in the same industry may have different tasks, interactions 
between equipment and tool dimensions, and work activities [25]. In the present study, a majority of men workers (30.5\%) were assigned to tasks that involved the handling of heavy objects, while fewer women workers (10.4\%) were. Therefore, it is possible that men workers had a higher opportunity of exposure to force risk compared with women. Furthermore, the results of present study from the first regression model found that, after adjustment for putative confounding factors including age, and posture was a risk factor for shoulder symptoms in men, whereas repetition was the major risk factor in women. The results of present study from the second regression model found that repetition, posture and force (approximately significant) were risk factors for shoulder symptoms in men, whereas posture (approximately significant) was the risk factor in women. Further investigation is needed to elucidate whether specific task assignments are associated with shoulder symptoms. About the posture and shoulder symptoms in women, earlier studies among women workers in electronics factories revealed that shoulder symptoms were the most comment musculoskeletal disorders [28, 29]. Kilbom et al. indicated that flexion and abduction of the upper arm were associated with shoulder symptoms [28]. Miranda et al. found that the risk of chronic shoulder disorders was associated with working in awkward postures in women (adjusted $\mathrm{OR}=2.3$ ) [47]. The present findings are consistent with earlier women studies showing that posture (crude $\mathrm{OR}=2.42-2.52$; adjusted $\mathrm{OR}=2.12$, which was approximately significant) was associated with shoulder symptoms in women (Table 4).

The present study indicated that permanent psychological stress was a significant risk factor of shoulder symptoms for women, based on the univariable regression. The finding is consistent with an earlier study which found that women may have jobs with higher psychosocial stress (e.g. high demands, low control), negatively impacting the musculoskeletal health [25]. Although the biological pathway for shoulder disorders are biomechanical, the psychological factor (e.g. work stress) may function as an intermediating factor affecting these ergonomic risk factors [34]. Two possible reasons accounting for the association between psychological stress and shoulder symptoms for women is that the hardness of shoulder muscle for women was larger than that of the men, and women were more sensitive to symptoms of their shoulder [48]. Furthermore, women reported higher levels of work overload, stress, and conflict than men because of the combined stress from the workplace and family (e.g. taking care of children) [49]. Women may accumulate risk factors related to work activities and activities of daily living, thus high job demand contributed to the development of chronic neck and shoulder pain independently of age [42]. The association between psychological stress and shoulder symptoms in women was not significant after multiple regression, and only repetition and force were associated. The present findings are inconsistent with earlier studies, and it is possible that the difference in assessing methods of psychological stress, which the single-item question on the frequency of stress at work, was applied in the study. Further investigation is needed to explore the issue using the different psychosocial stress model (e.g. job demand-control model, effort-reward imbalance model) for high risk group in the industry, instead of the single-item question.

Age is a predictor for shoulder symptoms in earlier studies $[47,50]$. The reason may be possibly related to the pathophysiological mechanisms of increasing degeneration of the shoulder tendons and the development of osteoarthrosis in shoulder joints [33,45]. Although aging may play a role for shoulder symptoms in the working population, contradictory findings have been indicated among some working populations exposed to high biomechanical risks [33]. For example, Silverstein et al. indicated that age was marginally significant for shoulder disorders [51]. The present study found that age is a risk factor for shoulder symptoms only for men, possibly because the modification of the age effect was different for different gender [33]. This present finding of examining subacromial impingement syndrome was similar to that of earlier studies that showed subacromial impingement syndrome was a common cause of musculoskeletal pain in the general working population $[12,33,51]$, and the correlation between shoulder symptoms and clinical signs of the rotator cuff tendinitis by physical examination was found [52].

There were several limitations that should be noted. First, this was a study in a single facility and the generalizability of this study requires further assessment. Second, the cross-sectional design restricts the inference of causal relationships and can only determine the association between relevant risk factors and shoulder symptoms. Third, the multivariable logistic regression model did not consider other potential confounding variables for shoulder symptoms, such as lack of sufficient 
rest, work organization factors, physical activity in spare time, muscular endurance in the arms, and job satisfaction [29, 50, 53]. Fourth, ergonomic risk factors analyzed for the repetition, posture, and force were only for more than 2 hours per shift; thus, one risk factor or combined risk factors with less this duration was not included. Thus, the results of present study may be underestimated. Fifth, physical examination for subacromial impingement syndrome was only performed among workers with shoulder symptoms. The positive rate of subacromial impingement syndrome remains uncertain in workers without shoulder symptoms, and in the viewpoint of early prevention, further examination for non-shoulder symptom workers may explore the subclinical shoulder cases. Further investigation is needed to assess work-related shoulder disorders, such as integrating comprehensive exposure assessment in intensity, duration, and frequency of ergonomic risk factors. This work may help our understanding of the pathophysiological mechanisms of shoulder disorders as well as attributional fractions of relevant risk factors. Studies to improve the knowledge of gender and the physical and psychosocial aspects of job interactions could enhance workplace job design and policy on the prevention of work-related shoulder disorders.

\section{Conclusions}

In the electronics industry, repetition and posture were important risk factors for shoulder disorders. The risk showed the gender difference, and force was more important for shoulder disorders in men, compared with women. Vibration was less important for shoulder disorders in the industry. There was the significant combined effect of similar ergonomic risks for shoulder disorders. Therefore, future ergonomic risk assessment for shoulder disorders may include at least the following aspects: (1) personal factors; (2) repetition; (3) posture; (4) psychological stress in the electronics industry. The genderstratified analyses is needed to consider the gender effect. The information may be a useful reference in the working environment to help multifactorial intervention strategies to reduce the risk of shoulder disorders. The development of a program for the early detection and prevention of shoulder symptoms in this working environment is warranted. The gender difference may be taken into consideration for preventive strategies and relevant occupational health policy of shoulder disorders. Future large-scale studies with longitudinal follow-up are warranted to further elucidate the impacts of personal factors, ergonomic risks, and psychological stress on the shoulder disorders of workers in the electronics industry.

\section{Abbreviations}

\section{TFT-LCD}

thin film transistor liquid crystal display

OR

odds ratios

95\% Cl

95\% confidence interval

PAR

Population attributable risk

\section{Declarations}

\section{Ethics approval and consent to participate}

The study was performed in line with the principles of the Declaration of Helsinki. Approval was granted by the Ethics Committee of National Taiwan University Hospital (201005047R). Informed consent was obtained from all individual participants included in the study.

\section{Consent for publication}

Not applicable. 


\section{Availability of data and materials}

The datasets used and/or analysed during the current study are available from the corresponding author on reasonable request.

\section{Competing interests}

The authors declare that they have no conflict of interest.

\section{Funding}

This study was funded by the research grants from National Taiwan University Hospital (NTUH.100-N1704, NTUH. 108S4433).

\section{Author Contributions}

PCC, YLG and TGW conceptualized and designed the study. PCC collected the data and performed the analyses. PCC, YLG and TGW interpreted the data. PCC wrote the manuscript. YLG and TGW critically commented the manuscript. All authors read and approved the final manuscript.

Acknowledgments: We are appreciative of the participation and compliance of all study participants. We express our sincerely gratitude to all staff members of this study who collaborated with us during the study especially Dr. Tun-Jen Hsiao. English Editing was provided by the Department of Medical Research at National Taiwan University Hospital.

\section{References}

1. International Labor Organization. Ups and Downs in the Electronics Industry: Fluctuating Production and the Use of Temporary and Other Forms of Employment. 2014. http://www.ilo.org/wcmsp5/groups/public/--ed_dialogue/-sector/documents/meetingdocument/wcms_317267.pdf. Accessed 01 Sep 2020.

2. Directorate-General of Budget. Number of employees in the electronics industry. 2016. https://www.stat.gov.tw/np.asp?ctNode=522. Accessed 01 Sep 2020.

3. Kim MH, Kim H, Paek D. The health impacts of semiconductor production: an epidemiologic review. Int J Occup Environ Health. 2014;20:95-114.

4. Smith V, English JSC. The electronics industry. In: Rustemeyer T, Elsner P, John S-M, Maibach HI, editors. Kanerva's Occupational Dermatology. Heidelberg: Springer; 2012. pp. 661-74.

5. Yu W, Lao XQ, Pang S, Zhou J, Zhou A, Zou J, Mei L, Yu IT. A survey of occupational health hazards among 7,610 female workers in China's electronics industry. Arch Environ Occup Health. 2013;68:190-5.

6. Huang WL, Guo YL, Chen PC, Wang J, Chu PC. Association between Emotional Symptoms and Job Demands in an Asian Electronics Factory. International journal of environmental research and public health. 2017;14.

7. Chee HL, Rampal KG, Chandrasakaran A. Ergonomic risk factors of work processes in the semiconductor industry in Peninsular Malaysia. Industrial health. 2004;42:373-81.

8. Pocekay D, McCurdy SA, Samuels SJ, Hammond SK, Schenker MB. A cross-sectional study of musculoskeletal symptoms and risk factors in semiconductor workers. Am J Ind Med. 1995;28:861-71.

9. Lu CW, Yao CC, Kuo CW. The ergonomics approach for thin film transistor-liquid crystal display manufacturing process. Work (Reading Mass). 2012;41(Suppl 1):5627-30.

10. Pullopdissakul S, Ekpanyaskul C, Taptagaporn S, Bundhukul A, Thepchatri A. Upper extremities musculoskeletal disorders: prevalence and associated ergonomic factors in an electronic assembly factory. Int J Occup Med Environ Health. 2013;26:751-61. 
11. Widanarko B, Legg S, Devereux J, Stevenson M. The combined effect of physical, psychosocial/organisational and/or environmental risk factors on the presence of work-related musculoskeletal symptoms and its consequences. Applied ergonomics. 2014;45:1610-21.

12. Lapointe J, Dionne CE, Brisson C, Montreuil S. Interaction between postural risk factors and job strain on self-reported musculoskeletal symptoms among users of video display units: a three-year prospective study. Scand J Work Environ Health. 2009;35:134-44.

13. Frost P, Bonde JP, Mikkelsen S, Andersen JH, Fallentin N, Kaergaard A, Thomsen JF. Risk of shoulder tendinitis in relation to shoulder loads in monotonous repetitive work. Am J Ind Med. 2002;41:11-8.

14. Sun YQ, Mao LF, Feng JL, Xu BQ, Luo C, Ni CH. [Investigation on occupational stress of workers in clean workshops of electric company]. Zhonghua lao dong wei sheng zhi ye bing za zhi = Zhonghua laodong weisheng zhiyebing zazhi = Chinese. journal of industrial hygiene occupational diseases. 2013;31:504-7.

15. Yeh WY, Cheng Y, Chen CJ. Social patterns of pay systems and their associations with psychosocial job characteristics and burnout among paid employees in Taiwan. Social science \& medicine (1982). 2009;68:1407-1415.

16. Ostergren PO, Hanson BS, Balogh I, Ektor-Andersen J, Isacsson A, Orbaek P, Winkel J, Isacsson SO. Incidence of shoulder and neck pain in a working population: effect modification between mechanical and psychosocial exposures at work? Results from a one year follow up of the Malmo shoulder and neck study cohort. J Epidemiol Commun Health. 2005;59:721-8.

17. Kuorinka I, Jonsson B, Kilbom A, Vinterberg H, Biering-Sorensen F, Andersson G, Jorgensen K. Standardised Nordic questionnaires for the analysis of musculoskeletal symptoms. Applied ergonomics. 1987;18:233-7.

18. Sluiter JK, Rest KM, Frings-Dresen MH. Criteria document for evaluating the work-relatedness of upper-extremity musculoskeletal disorders. Scand J Work Environ Health. 2001;27(Suppl 1):1-102.

19. Health Safety Executive. Upper limb disorders in the workplace. Norwich: HSE Books; 2002.

20. David GC. Ergonomic methods for assessing exposure to risk factors for work-related musculoskeletal disorders. Occupational medicine (Oxford, England). 2005;55:190-199.

21. Rosengren A, Hawken S, Ounpuu S, Sliwa K, Zubaid M, Almahmeed WA, Blackett KN, Sitthi-amorn C, Sato H, Yusuf S. Association of psychosocial risk factors with risk of acute myocardial infarction in 11119 cases and 13648 controls from 52 countries (the INTERHEART study): case-control study. Lancet. 2004;364:953-62.

22. Gomez MA, Merz NB, Eastwood JA, Pepine CJ, Handberg EM, Bittner V, Mehta PK, Krantz DS, Vaccarino V, Eteiba W, et al. Psychological stress, cardiac symptoms, and cardiovascular risk in women with suspected ischaemia but no obstructive coronary disease. Stress: journal of the International Society for the Investigation of Stress; 2020.

23. Skarpsno ES, Nilsen TIL, Sand T, Hagen K, Mork PJ. Physical work exposure, chronic musculoskeletal pain and risk of insomnia: longitudinal data from the HUNT study, Norway. Occupational and environmental medicine. 2018;75:421426.

24. Coughlin SS, Benichou J, Weed DL. Attributable risk estimation in case-control studies. Epidemiol Rev. 1994;16:51-64.

25. Silverstein B, Fan ZJ, Smith CK, Bao S, Howard N, Spielholz P, Bonauto D, Viikari-Juntura E. Gender adjustment or stratification in discerning upper extremity musculoskeletal disorder risk? Scand J Work Environ Health. 2009;35:11326.

26. Klussmann A, Steinberg U, Liebers F, Gebhardt H, Rieger MA. The Key Indicator Method for Manual Handling Operations (KIM-MHO) - evaluation of a new method for the assessment of working conditions within a crosssectional study. BMC Musculoskelet Disord. 2010;11:272.

27. Kuo CWL, C.W. Ergonomics hazards analysis and improvement design of module assembly process in TFT-LCD factories. Journal of Ergonomic Study. 2008;10:21-9.

28. Kilbom Å, Persson J, Jonsson BG. Disorders of the cervicobrachial region among female workers in the electronics industry. Int J Ind Ergon. 1986;1:37-47.

Page $17 / 20$ 
29. Jonsson BG, Persson J, Kilbom Å. Disorders of the cervicobrachial region among female workers in the electronics industry: a two-year follow up. Int J Ind Ergon. 1988;3:1-12.

30. Aghilinejad M, Azar NS, Ghasemi MS, Dehghan N, Mokamelkhah EK. An ergonomic intervention to reduce musculoskeletal discomfort among semiconductor assembly workers. Work (Reading Mass). 2016;54:445-50.

31. Chandrasakaran A, Chee HL, Rampal KG, Tan GL. The prevalence of musculoskeletal problems and risk factors among women assembly workers in the semiconductor industry. Med J Malay. 2003;58:657-66.

32. Mork R, Falkenberg HK, Fostervold KI, Thorud HMS. Visual and psychological stress during computer work in healthy, young females-physiological responses. Int Arch Occup Environ Health. 2018;91:811-30.

33. Roquelaure Y, Bodin J, Ha C, Petit Le Manac'h A, Descatha A, Chastang JF, Leclerc A, Goldberg M, Imbernon E. Personal, biomechanical, and psychosocial risk factors for rotator cuff syndrome in a working population. Scand J Work Environ Health. 2011;37:502-11.

34. van der Molen HF, Foresti C, Daams JG, Frings-Dresen MHW, Kuijer P. Work-related risk factors for specific shoulder disorders: a systematic review and meta-analysis. Occup Environ Med. 2017;74:745-55.

35. Sutinen P, Toppila E, Starck J, Brammer A, Zou J, Pyykko I. Hand-arm vibration syndrome with use of anti-vibration chain saws: 19-year follow-up study of forestry workers. Int Arch Occup Environ Health. 2006;79:665-71.

36. Issever H, Aksoy C, Sabuncu H, Karan A. Vibration and its effects on the body. Medical principles practice: international journal of the Kuwait University Health Science Centre. 2003;12:34-8.

37. Johanning E, Landsbergis P, Fischer S, Luhrman R. Back Disorder and Ergonomic Survey Among North American Railroad Engineers. Transportation Research Record: Journal of the Transportation Research Board. 2004;1899:14555.

38. van der Windt DA, Thomas E, Pope DP, de Winter AF, Macfarlane GJ, Bouter LM, Silman AJ. Occupational risk factors for shoulder pain: a systematic review. Occup Environ Med. 2000;57:433-42.

39. Seidler A, Bolm-Audorff U, Petereit-Haack G, Ball E, Klupp M, Krauss N, Elsner G. Work-related lesions of the supraspinatus tendon: a case-control study. Int Arch Occup Environ Health. 2011;84:425-33.

40. Hagberg $\mathrm{M}$, Wegman $\mathrm{DH}$. Prevalence rates and odds ratios of shoulder-neck diseases in different occupational groups. Br J Ind Med. 1987;44:602-10.

41. Chee HL, Rampal KG. Work-related musculoskeletal problems among women workers in the semiconductor industry in Peninsular Malaysia. Int J Occup Environ Health. 2004;10:63-71.

42. Cassou B, Derriennic F, Monfort C, Norton J, Touranchet A. Chronic neck and shoulder pain, age, and working conditions: longitudinal results from a large random sample in France. Occup Environ Med. 2002;59:537-44.

43. van Rijn RM, Huisstede BM, Koes BW, Burdorf A. Associations between work-related factors and specific disorders of the shoulder-a systematic review of the literature. Scand J Work Environ Health. 2010;36:189-201.

44. Cudlip AC, Meszaros KA, Dickerson CR. The Influence of Hand Location and Force Direction on Shoulder Muscular Activity in Females During Nonsagittal Multidirectional Overhead Exertions. Human factors. 2016;58:120-39.

45. Miranda H, Viikari-Juntura E, Martikainen R, Takala EP, Riihimaki H. A prospective study of work related factors and physical exercise as predictors of shoulder pain. Occup Environ Med. 2001;58:528-34.

46. Razmjou H, Lincoln S, Macritchie I, Richards RR, Medeiros D, Elmaraghy A. Sex and gender disparity in pathology, disability, referral pattern, and wait time for surgery in workers with shoulder injury. BMC Musculoskelet Disord. 2016;17:401.

47. Miranda H, Punnett L, Viikari-Juntura E, Heliovaara M, Knekt P. Physical work and chronic shoulder disorder. Results of a prospective population-based study. Ann Rheum Dis. 2008;67:218-23.

48. Kimura T, Tsuda Y, Uchida S, Eboshida A. Association of perceived stress and stiff neck/shoulder with health status: multiple regression models by gender. Hiroshima journal of medical sciences. 2006;55:101-7. 
49. Lundberg U, Mardberg B, Frankenhaeuser M. The total workload of male and female white collar workers as related to age, occupational level, and number of children. Scand J Psychol. 1994;35:315-27.

50. Sommerich CM, McGlothlin JD, Marras WS. Occupational risk factors associated with soft tissue disorders of the shoulder: a review of recent investigations in the literature. Ergonomics. 1993;36:697-717.

51. Silverstein BA, Bao SS, Fan ZJ, Howard N, Smith C, Spielholz P, Bonauto D, Viikari-Juntura E. Rotator cuff syndrome: personal, work-related psychosocial and physical load factors. Journal of occupational environmental medicine. 2008;50:1062-76.

52. Kaergaard A, Andersen JH, Rasmussen K, Mikkelsen S. Identification of neck-shoulder disorders in a 1 year follow-up study. Validation Of a questionnaire-based method. Pain. 2000;86:305-10.

53. Barnekow-Bergkvist M, Hedberg GE, Janlert U, Jansson E. Determinants of self-reported neck-shoulder and low back symptoms in a general population. Spine. 1998;23:235-43.

\section{Figures}

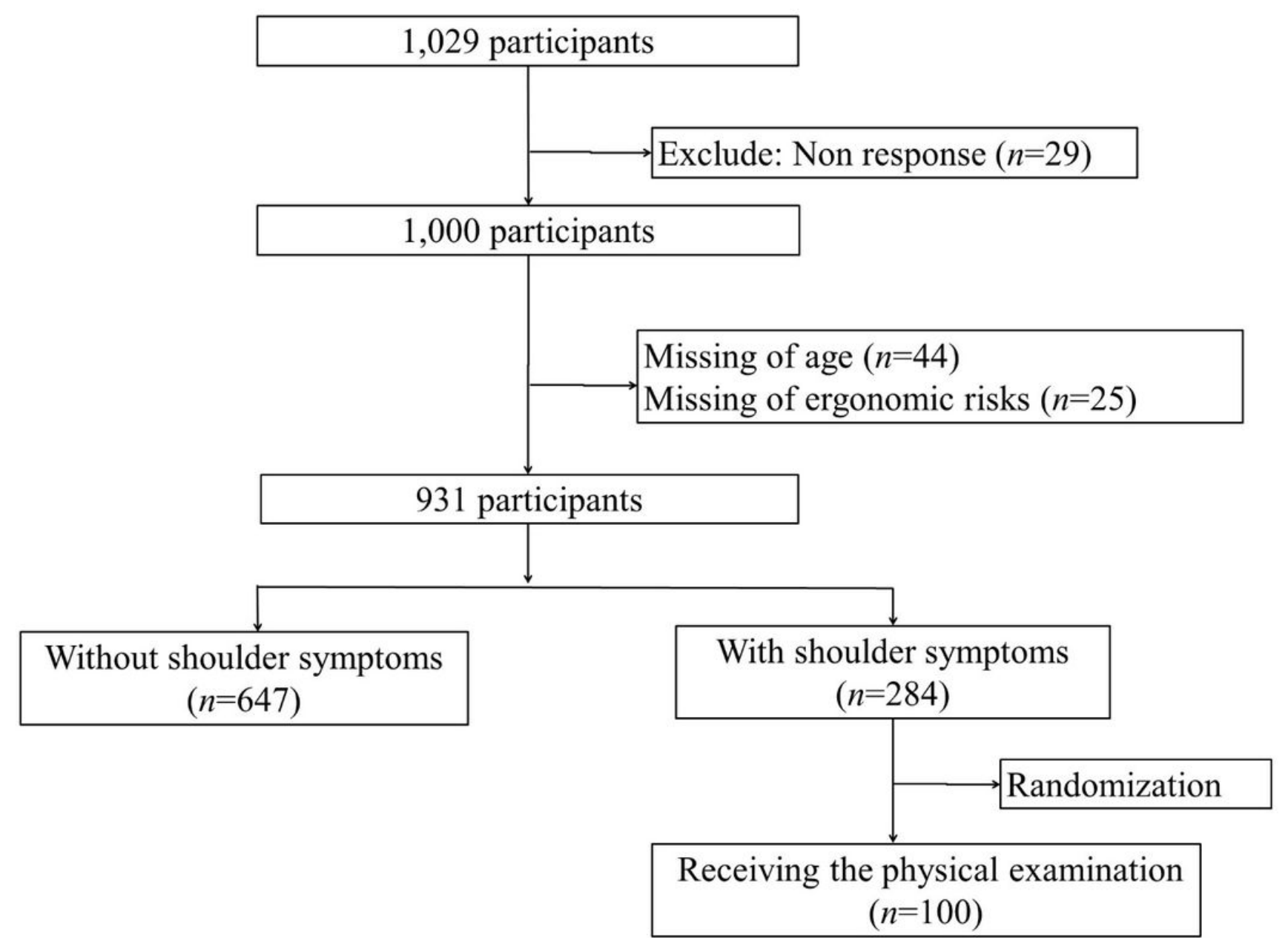

Figure 1

Flowchart of recruiting study population 

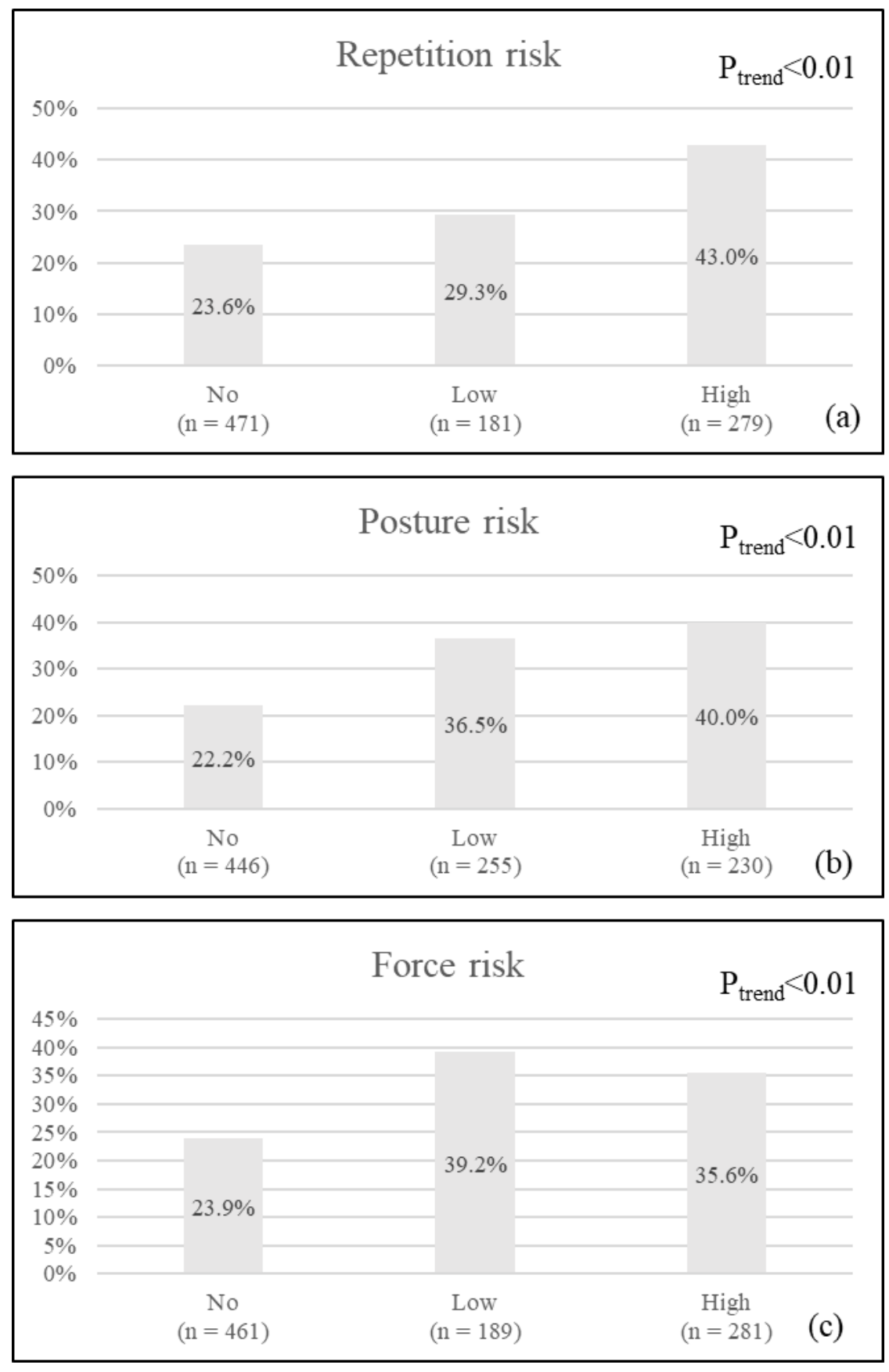

\section{Figure 2}

Association between the proportions of shoulder symptoms and the number of ergonomic risks: (a) Repetition risk, (b) Posture risk, (c) Force risk. Footnotes: The definition of high, low, and no were $\geq 3$ items, 1 - 2 items, and no item of repetition, posture, and force risks, respectively; Ptrend: $P$ for trend 